Научная статья

УДК 316.342 .5

DOI 10.18101/2306-630X-2020-2-33-40

\title{
КОНСЕРВАТИВНО-ПУБЛИЦИСТИЧЕСКОЕ НАПРАВЛЕНИЕ В ИЗУЧЕНИИ ОТЕЧЕСТВЕННОЙ ЭЛИТЫ В КОНЦЕ ХІХ — НАЧАЛЕ ХХ В.
}

\author{
(C) Покатов Дмитрий Валериевич \\ доктор социологических наук, доцент, \\ заведующий кафедрой истории, теории и прикладной социологии, \\ Саратовский национальный исследовательский \\ государственный университет имени Н. Г. Чернышевского \\ Россия, 410012, г. Саратов, ул. Астраханская, 83 \\ dvpokatov@gmail.com
}

\begin{abstract}
Аннотация. В статье рассматриваются особенности социологических и социальнофилософских воззрений на элиту представителей такого достаточно своеобразного направления в отечественной социально-философской мысли, как консервативнопублицистическое. Выявляются базовые его характеристики, дается краткая типология направлений социально-философской мысли в изучении элит. Отмечается, что в работах выдающихся представителей социальной и социально-философской мысли конца XIX - начала XX в., затрагивается самый широкий круг вопросов и проблем онтологического, аксиологического, социально-политического плана, в том числе различные аспекты разноплановой элитной проблематики. Как правило, их объединяет достаточно абстрактный нормативистский подход. Также анализ элитных групп был обращен зачастую (за редким исключением) не к настоящему, а к обществу будущего, что, конечно, придавало ему значительную специфику. В творчестве представителей консервативно-публицистического направления наиболее заметна тенденция анализа элиты как особого высшего, правящего слоя, административной прослойки светского или религиозного характера, направляющей развитие общества и выполняющей все важнейшие управленческие функции и действующей преимущественно в институтах власти либо тесно связанной с ними. Значительное внимание в работе уделяется анализу подходов к изучению параметров элиты и ее роли в обществе, представленных в работах таких видных представителей консервативно-публицистического направления, как В. С. Соловьев и Н. О. Лосский.

Ключевые слова: элита; политическая элита; интеллигенция; аристократия; консервативно-публицистическое направление; меритократические теории; В. С. Соловьев; Н. О. Лосский; общество; теократическое общество; монархия.
\end{abstract}

\section{Для цитирования}

Покатов Д. В. Консервативно-публицистическое направление в изучении отечественной элиты в конце XIX — начале XX в. // Евразийство и мир. 2020. № 2. С. 33-40.

В последние годы продолжает расти интерес к изучению творчества многих крупнейших представителей отечественной социально-философской и социологической мысли. Долгие годы, вплоть до конца 80-х гг. прошлого века, многие из них были незаслуженно обойдены вниманием из-за идей, которые противоре- 
чили официальным установкам господствовавшей в советский период идеологической доктрины. Однако формирование новых методологических ориентаций невозможно без учета того значительного теоретического багажа, который был накоплен отечественной социально-философской и социологической мыслью предшествовавшего Октябрьской революции 1917 г. периода. Это тем более важно, что многие затрагиваемые в работах отечественных философов и социологов, особенно переходного периода конца XIX-XX вв., вопросы достаточно созвучны современности. Это в полной мере относится и к проблемам инновационного развития общества, его факторов и условий, становлению демократии и народного представительства, роли элиты в общественном переустройстве, улучшении процесса функционирования институтов власти и управления и многим другим.

Начавшийся с 60-х гг. XIX в. период становления отечественной социологической науки и ее относительно спокойного развития был, по существу, прерван контрреформами императора Александра III. Следствием этого явился запрет на саму постановку многих актуальных социальных проблем. Основные носители социологического знания, за исключением Н. И. Кареева и еще нескольких ученых, вынуждены были эмигрировать и продолжить свою деятельность за границей. Постепенно место социологических учений стали занимать различные социально-философские концепции, среди которых доминировали благодаря поддержке властных институтов консервативные и охранительные школы и направления.

Данный процесс своеобразной научной «циркуляции», как справедливо отмечает ряд современных исследователей, был достаточно характерен для российской социальной мысли [1, с. 235]. В результате социология, призванная, по сути, быть объективной и независимой от политики, на протяжении своего недолгого существования испытывала сильнейшее давление со стороны власти, которое и приводило то к независимому ее существованию, то к запретам и гонениям, вынуждавшим эмигрировать ее виднейших представителей.

Вследствие отмеченных выше причин, в 80-е гг. XIX в. и вплоть до Февральской революции 1917 г. господствующие позиции в социальной мысли занимали именно социально-философские школы и направления. В процессе своего развития они приобрели ряд характерных черт и особенностей, некоторые из которых рассмотрели такие выдающие отечественные мыслители, как Н. О. Лосский и А. Ф. Лосев. Так, Н. О. Лосский справедливо отмечает, что «русской философии свойственно острое чувство реальности и чуждо стремление рассматривать содержание внешних перцепций как нечто психическое и субъективное» [2, с. 513].

Другой выдающийся русский мыслитель А. Ф. Лосев справедливо замечал, что основу западноевропейской философии составляет ratio (разум), в то время как русская философская мысль, развивавшаяся на основе греко-православных представлений, в свою очередь, во многом заимствованных у античности, кладет в основание всего Логос, который более метафизичен и божественен [3, с. 125].

Говоря об особенностях российской социальной и социально-философской мысли, отметим также и то, что в работах ее представителей затрагивается самый широкий круг вопросов и проблем онтологического, аксиологического, социально- 
Покатов Д. В. Консервативно-публицистическое направление в изучении отечественной элиты в конце XIX — начале XX в.

политического плана. Среди них не были исключением и различные аспекты многогранной элитной проблематики.

Начиная с середины XIX в. к анализу элиты стали все чаще обращаться мыслители, представляющие различные направления социально-философской мысли. В работах представителей социальной мысли того периода доминировал, как правило, достаточно абстрактный нормативистский подход, при котором элита в целом и отдельные ее группы в частности, рассматривались как сообщества, сосредотачивающие в своем составе интеллектуалов, обладающих высокими моральными и интеллектуальными характеристиками, которые к тому же пытались действовать в интересах общего блага. При этом, как правило, анализ элиты был обращен зачастую (за редким исключением) не к настоящему, к обществу будущего, что, конечно, придавало ему значительную специфику.

В последние годы предпринимались успешные попытки типологизировать социально-философские школы и направления, изучавшие различные аспекты социального и социально-политического развития общества, в том числе и проблемы развития системы государственного управления и роли отдельных субъектов, в том числе элиты. В частности, С. Н. Малявин считает, что принцип деления на направления лежит в методологической плоскости, дающей четкие отличительные признаки философии и социологии. Среди социально-философских направлений он выделяет три базовые: метафизики (Б. Н. Чичерин), почвенники (А. С. Хомяков, И. В. Киреевский, К. С. Аксаков, Н. Я. Данилевский, К. Н. Леонтьев, К. П. Победоносцев, Л. А. Тихомиров, В. С. Соловьев, Н. А. Бердяев, С. Л. Франк, евразийцы) и материалисты (Н. Г. Чернышевский и А. И. Герцен) [1, с. 227]. Марксизм в силу того, что он имеет отношение как к социальной философии в аспекте диалектического материализма, так и к социологии в своем историческом материализме, выделяется в отдельное направление.

Применительно к элите, как думается, более оправданно использовать не столько методологический подход, а социально-политическую и идеологическую направленность концепций и теорий, более свойственную направленности деятельности и роли элиты, что позволяет говорить о таких направлениях, как консервативно-публицистические, к которым принадлежали ряд представителей почвеннического направления в философии, в том числе В. С. Соловьев, Н. О. Лосский, интегральные (Б. Н. Чичерин) и философско-меритократические (Н. А. Бердяев, Н. Н. Алексеев, Г. П. Федотов и др.).

В творчестве представителей первого, консервативно- публицистического, направления наиболее заметна тенденция анализа элиты как особого высшего, правящего слоя, административной прослойки светского или религиозного характера, направляющей развитие общества и выполняющей зачастую все важнейшие управленческие функции и действующей преимущественно в институтах власти, либо тесно связанной с ними. При оценке элиты многие авторы подчеркивали идеи ее сословного происхождения и говорили о необходимости сохранения привилегий.

Среди представителей консервативно-публицистического направления в рассматриваемый период конца XIX - начала XX в. особо можно выделить творчество В. С. Соловьева и Н. О. Лосского. 
На первый взгляд творчество В. С. Соловьева достаточно далеко от социологии. Однако, как верно отмечает С. Н. Малявин, при рассмотрении общества в целом взгляды философа были во многом созвучны идеям, отстаиваемым О. Контом, прежде всего, в предпринимаемых обоими учеными попытках связать развитие общества с идеей прогресса $[1$, c. 81$]$.

В представлении В. С. Соловьева строение общества включает в себя три базовых компонента: народ в тесном смысле - класс сельский или земледельческий, затем класс городской и, наконец, «класс лучших людей, общественных деятелей и вождей народа, показателей пути» [4, с. 379].

По глубокому убеждению В. С. Соловьева, народ занимал низшие ступени социальной лестницы, занимаясь земледелием, и стремясь поддерживать прочную связь с высшими религиозными слоями [4, с. 337]. Городские слои всегда выполняют посредствующие функции. И лишь «лучшие люди», в представлении ученого, составляли высший класс, который может выступать вождями народа и одновременно свободными служителями государства и церкви.

Идеалом для ученого выступает теократическое общество, в котором должны быть интегрированы три элемента: высший религиозный авторитет («вселенский первосвященник»), обладающий значительным духовным влиянием и выполняющий функции поддержания определенных ценностей, светская власть и слой мыслителей-философов, выступающих (если вспомнить выдающегося итальянского социолога В. Парето) контрэлитой общества, реализующей, прежде всего, духовные приоритеты $[5$, с. 458,465$]$. Анализируя высшую верховную власть, В. С. Соловьев приходил к выводу, что христианская монархия должна представлять собой «самодержавие совести». При этом носитель верховной власти, порученной ему от Бога правды и милости, не подлежит никаким ограничением, кроме нравственных. Он может все, что согласуется с совестью. И в этом он, по мысли В. С. Соловьева, отличен от восточных деспотов, ограниченных неподвижными традиционными учреждениями, и римских императоров, знающих только физические границы своему произволу и не отвечающих за свои действия ни перед людьми, ни перед Богом [6, с. 301].

Несмотря на общую консервативную направленность взглядов, ряд идей ученого был созвучен меритократическому направлению, подчеркивавшему ценностную природу элиты, ее интеллектуальное и моральное превосходство. В этой связи В. С. Соловьев также считал, что государство есть необходимое условие человеческой образованности, культурного прогресса. Отсюда одной из главных задач элиты должна быть реализация нравственных начал в обществе и политике, как внутренней, так и внешней. Исходя из этого, полагал ученый, элита должна способствовать тому, чтобы распространять нравственное начало и на область международных отношений, изменять их в направлении большей справедливости и человеколюбия [6, с. 302]. Однако реализация данных важных направлений пока далека от своего идеала. Здесь, как раз проявился реализм позиции В. С. Соловьева. Это связано в первую очередь с тем, что состав правящей элиты далек от описанной В. С. Соловьевым модели. Представительство в нем 
Покатов Д. В. Консервативно-публицистическое направление в изучении отечественной элиты в конце XIX — начале XX в.

интеллектуальных кругов, в том числе упоминаемой им вслед за Платоном интеллектуальной, научной элиты, все еще недостаточно.

Данный факт подтверждает и современный этап развития. Начиная с конца 80 -х гг. XX в. количество интеллигенции в составе, в частности, правящей элиты несколько увеличилось, чему во многом способствовала трансформация господствовавшей в советский период номенклатурной системы со значительным числом фильтров в виде учета партийной принадлежности, социального происхождения, опыта партийно-политической деятельности. Отказ от них привел к некоторому обновлению элиты. Но преувеличивать это не стоит. Как правило, представители интеллигенции не обладали необходимыми связями и опытом работы в составе институтов власти. Также многие представители интеллигенции не стремились оставить интеллектуальное творчество, которое было им привычно и где прошла основная часть их сознательной жизни, и обменять его на весьма неспокойное и во многом кратковременное политическое поприще. В настоящее время численный состав представителей интеллигенции в составе политической элиты несколько возрос. Общая численность представителей интеллигенции, согласно проведенному автором анализу 679 политических деятелей, опубликованных на сайтах президента РФ, палат Федерального Собрания РФ, в правящем элитном слое составляет сегодня $33,17 \%$, в том числе среди депутатов Государственной Думы - 33,9\%. В то же время господствовавшая ранее прослойка хозяйственников, включающая руководителей предприятий бывшего ВПК и АПК, менеджеров фирм, банковско-финансовую олигархию, составляет в целом сегодня на федеральном уровне $38,5 \%{ }^{1}$.

Возвращаясь к анализу теории В. С. Соловьева, можно говорить, что как далек от идеала состав элиты, так же, считает В. С. Соловьев, далека и направленность деятельности высшего элитного слоя, которая, с одной стороны, приводила к угнетению народа, а с другой - к соперничеству с государственной и церковной властью. Вследствие этого формирование полноценной, эффективной политической элиты может произойти только в будущем, когда произойдут некоторые изменения «гражданского строя» [7, с. 145, 157].

В целом по своей консервативной направленности концептуальный подход В. С. Соловьева применительно к анализу элиты во многом совпадал с теорией Н. О. Лосского.

Свою теорию «иерархического персонализма» Н. О. Лосский рассматривал как «учение о монархическом строении вселенной». Однако, по его мнению, этот «онтологический монархизм» совсем не похож на «политический монархический строй человеческого общества». В своих работах мыслитель подчеркивал, что «государство сохраняет жизнеспособность и настолько, насколько оно жизненно» в том случае, когда во главе его находится начало, которое можно назвать «Душою народа» $[8$, c. 475]. Это начало не сводимо к конкретному индивиду, даже если он и является монархом. Как замечает ученый, «фактически даже наиболее самов${ }^{1}$ Президент РФ [Электронный pecypc]. URL: http: //www. kremlin.ru (дата обрашения: 10.09.2020); Государственная Дума Федерального Собрания Российской Федерации [Электронный pecypc]. URL/ http: //www. duma.gov.ru (дата обрашения: 10.09.2020). 
ластный монарх принимает большинство решений в согласии с так называемым "правительственным целым", то есть так, что они вырабатываются сверхчеловеческим единством» [8, с. 475]. По мере возрастания дифференциации общества и усовершенствования механизма государственного управления власть, как считал Н. О. Лосский, может все больше эволюционировать к республиканским формам $[8$, c. 475$]$.

При этом, допуская возможность перехода к более демократическим формам, Н. О. Лосский подчеркивал, что сегодня никому, вероятно, не придет в голову говорить, что современная демократия есть идеально совершенный способ организации государства. Он соглашается с другим выдающимся отечественным мыслителем И. А. Ильиным в том, что демократия наиболее хороша тогда, когда осуществляет аристократию или отбор в институты верховной власти лиц, наиболее духовно одаренных для государственной деятельности. Формирование аристократии, отбор в ее ряды лиц должен вестись, по его мнению, на основе организации корпоративных, профессиональных и иных форм представительства. Прежде всего при отборе в элиту, по его мнению, необходимо учитывать услуги, оказанные обществу и свидетельствующие о моральной готовности представителя элиты выполнять свои функции. Затронув достаточно важную проблему рекрутирования элитных слоев, Н. О. Лосский не обошел стороной и важный вопрос о направленности деятельности элиты. Он особо подчеркивал, что для решения стоящих на очереди проблем необходимо напряжение социального творчества, а также исключительное самоотвержение всех социальных слоев и классов общества и всех народов, чтобы найти приемлемые для всех, наиболее безболезненные способы примирения и совмещения разнородных ценностей. К последним он относил ценности национального самоопределения, сверхгосударственного единства, свободной хозяйственной инициативы, служения хозяйства общественному целому. Достаточно актуальным и сегодня выглядит его утверждение о том, что каждый гражданин с чуткой совестью и прозрением в будущее обязан во внутренней экономической жизни общества разрабатывать или, по крайней мере, поддерживать проекты и мероприятия, сочетающие в себе сохранение хозяйственной инициативы с устранением эксплуатации человека человеком, а во внешней жизни общества приветствовать всякий шаг в направлении к тому времени, когда деньги, ассигнуемые теперь на сооружение дредноута, изнашивающегося через 10 лет, можно будет употребить хотя бы на постройку десяти тысяч дешевых квартир, где 50 тысяч скромных тружеников получат светлое, сухое и теплое жилище вместо гнилых, сырых подвалов [8, с. 477-478].

Оценивая в целом деятельность элитных слоев, он справедливо отмечал, что такая аристократия духа не будет возвратом к абсолютной монархии, а будет свидетельствовать о движении в сторону новых форм организации власти и общества $[8$, с. 476$]$.

Подводя итог рассмотрению данного, достаточно своеобразного явления отечественной социально-философской и социологической мысли, каким выступают консервативно-публицистические концепции элиты, можно с уверенностью 
Покатов Д. В. Консервативно-публицистическое направление в изучении отечественной элиты в конце XIX — начале XX в.

говорить, что, несмотря на консервативный настрой некоторых суждений видных представителей данного направления, в их трудах были высказаны важные и плодотворные концепты, которые, без сомнения, могут быть использованы не только в практике рекрутирования элитных групп, но и стать важным вектором трансформации как всего общества, так и его политической подсистемы.

Лuтература $255 \mathrm{c}$.

1. Малявин С.Н. История русской социально-философской мысли. М.: Дрофа, 2003.

2. Лосский Н. О. История русской философии. М.: Советский писатель, 1991. 480 с.

3. Введенский А.И. [и др.] Судьбы русской философии // Очерки истории русской философии. Свердловск: Изд-во Урал. ун-та, 1991. 591 с.

4. Соловьев В.С. Духовные основы жизни // Соловьев В. С. Собрание сочинений. СПб.: Изд-во товарищества «Общественная польза», 1903. Т. 3. 667 с.

5. Соловьев В.С. История и будущность теократии // Соловьев В. С. Собрание сочинений. СПб.: Изд-во товарищества «Общественная польза», 1903. Т. 4. 586 с.

6. Соловьев В.С. Философская публицистика // Соловьев В. С. Антология мировой политической мысли: в 5 т. М.: Мысль, 1997. Т. 4. 829 с.

7. Соловьев В.С. Еврейство и христианский вопрос // Соловьев В. С. Собрание сочинений. СПб.: Изд-во товарищества «Общественная польза», 1903. Т. 3. 667 с.

8. Лосский Н. О. Органическое строение общества и демократия // Антология мировой политической мысли: в 5 т. М.: Мысль, 1997. Т. 4. 829 с.

\title{
CONSERVATIVE PUBLICISM IN THE STUDY OF THE DOMESTIC ELITE OF THE LATE $19^{\text {th }}-$ THE BEGINNING OF THE $20^{\text {th }}$ CENTURY
}

\author{
Dmitry V. Pokatov \\ Dr. Sci. (Sociol.), A/Prof., \\ Head of the Department of History, Theory and Applied Sociology, \\ Chernyshevsky Saratov National Research State University \\ 83 Astrakhanskaya St., Saratov 410012, Russia \\ dvpokatov@gmail.com
}

Abstract. The article considers the features of sociological and socio-philosophical views on the elite of such a rather peculiar trend in Russian socio-philosophical thought as conservative publicism. We have revealed its basic characteristics, given a brief typology of the social and philosophical thought in the study of elites. It is noted that works of the prominent representatives of social and socio-philosophical thought of the late 19 th - early 20th centuries touch upon the widest range of ontological, axiological, socio-political issues, including various aspects of diverse elite problems. The whole, they are united by a rather abstract normative approach. An analysis of elite groups was often (with rare exceptions) turned not to the present, but to the society of the future, that, of course, determined it specificity. The most noticeable tendency in the works of conservative publicists was the consideration of elite as a high, ruling stratum, having a secular or religious nature, directing the development of society, performing all the most important administrative functions and acting mainly in the institutions of power, or closely associated with them. We have paid considerable attention to the study of the elite 
parameters and its role in society, reflected in the works of such prominent conservative publicists as V. S. Solovyev and N. O. Lossky.

Keywords: elite; political elite; the intelligentsia; aristocracy, conservative publicistics; meritocratic theories; V. S. Solovyev; N. O. Lossky; society; theocratic society; monarchy.

Статья поступила в редакцию 30.11.2020; одобрена после рецензирования 07.12.2020; принята к публикации 11.12.2020. 